\title{
Lucha de élites en Argentina: La Unión Cívica Radical \\ en Mendoza (1890-1905)
}

Pablo Alberto Lacoste

Buenos Aires, Argentina

La evolución política de las naciones latinoamericanas ha estado signada secularmente por la inestabilidad. Las continuas rupturas de los procesos constitucionales han vulnerado la estabilidad jurídica necesaria para el desarrollo económico. Por este motivo, el estancamiento actual de los países latinoamericanos se encuentra estrechamente ligado a su crónica inestabilidad institucional. Teniendo en cuenta estos elementos, el presente trabajo se ha centrado en la República Argentina, tomando como caso referencial el comportamiento de las élites políticas en la provincia de Mendoza, entre 1890 y 1905. La muestra resulta apropiada por reunir las contradicciones existentes en todo el país en un caso acotado, diáfano y representativo.

Los estudios de las élites ocupan actualmente un lugar preferencial en las ciencias sociales. Durante décadas, los investigadores habían procurado explicar la evolución de la Historia en términos de lucha de clases; hicieron especial hincapié en la estructura económica para analizar a partir de allí las grandes transformaciones políticas. No obstante, los referentes empíricos plantearon una serie de límites a este punto de partida; fue preciso entonces enriquecer y ampliar la base teórica para resolver los nuevos problemas. A tal fin, se produjo un reflorecimiento de las teorías de élites.

Los estudios de las élites fueron desarrollados inicialmente por Mosca (1896) y Paretto (1901); se vigorizaron con los aportes de Michels (1915) y Max Weber (1921). ${ }^{1}$ En las décadas posteriores quedaron un tanto relegados, para reaparecer con fuerza en los '80. En la última década, el tema adquirió un creciente impulso, espe-

1 Mosca, Caetano: The ruling Class, New York, 1939 (1901). Paretto, Vilfredo: The Mind and Society. A Treatise on General Sociology. New York, 1935 (1898). Weber, Max: Economía y Sociedad. México, 1983 (1921). 
cialmente por los trabajos de Burton y Higley (1980, 1985, 1987). Las tendencias de los ' 90 parecen ratificar esta línea, con los nuevos estudios de Burton y Higley, a quienes se sumó Field, y las críticas de Lachmann (1990) y Cammack (1990). ${ }^{2}$

Las nuevas propuestas difieren en su definición de élite. La línea de Burton y Higley propone una definición amplia, incluyendo en la élite a "personas que en virtud de su autoridad en organizaciones dotadas de poder y movimientos de cualquier clase, son capaces de afectar las realizaciones políticas regular y sustancialmente". ${ }^{3}$ Para Lachmann, en cambio, "una élite puede ser definida como un grupo de gobernantes con capacidad de apropiación de los recursos de los sectores no pertenecientes a la élite que pertenecen a un aparato de organización distinto (distinct organizational apparatus)". ${ }^{4}$ En este trabajo seguimos la propuesta de Higley y Burton, para englobar dentro de la categoría de élites a los sectores conservadores y las dos alas de la Unión Cívica Radical (UCR). La propuesta de Lachmann no permitiría incluir el ala lencinista del radicalismo, y abriría un fecundo camino de interpretación pero desde otro ángulo, como veremos más tarde.

Uno de los problemas que la teoría de las élites propuesta por Higley y Burton procura abordar, es el fracaso de la instalación de regímenes estables en Latinoamérica. Los autores citados indican que la estabilidad o inestabilidad de un régimen no depende tanto del grado de industrialización, como de la capacidad de las élites por acordar reglas de juego político claras y estables, fenómeno que cristaliza en la "unificación consensuada". ${ }^{5}$ En la primera etapa de

2 Burton, Michael and Higley, John: Elite Settlements. "American Sociological Review", vol. 52, June 1987, págs. 295-307. Cammack, Paul: A critical Assessment of the new Elite paradigm. Ibídem, vol. 55, June 1990, págs. 415-420. Higley, John and Burton, Michael: The Elite variable in democratic Transitions and Breakdowns. Ibídem, vol. 54, February 1989, págs. 17-32. Higley, John; Burton, Michael and Field, Lowell: In defense of Elite theory: a reply to Cammack. Ibídem, vol. 55, June 1990, págs. 421-426. Lachmann, Richard: Class formation without class struggle: an elite conflict theory of the transition to capitalismo.- Ibídem, págs. 398-414.

3 Higley and Burton, The Elite variable..., pág. 18.

4 Lachmann, Class farmation..., pág. 401.

5 Burton and Higley, Elite Settlements, págs. 296-297. 
un estado nación, las élites se encuentran en un estadio de desunificación. Su evolución hacia la unificación consensuada puede darse de dos formas distintas: por el establecimiento de la élite (elite settlement) o por transformación en dos etapas (two step transformation).

La unificación por "establecimiento" surge cuando "algunas de las facciones en pugna, súbita y deliberadamente reorganizan sus relaciones negociando compromisos sobre sus desacuerdos básicos; consecuentemente, logran una unidad consensuada y echan las bases para un régimen democrático estable". 6 Por su parte, la segunda clase de unificación se desarrolla en dos etapas. La primera surge cuando algunas facciones en pugna ingresan en forma sostenida en una política de colaboración pacífica en la política electoral para movilizar una amplia mayoría electoral; por ello, ganan las elecciones reiteradamente y protegen sus intereses mediante el dominio del poder ejecutivo. En la segunda etapa, "la principal facción opositora a la coalición gobernante, se incorpora al acuerdo. Renuncia a cualquier camino para alcanzar el poder distinto de la lucha electoral (por ejemplo, los golpes o revoluciones), abandona algunos elementos ideológicos y adopta esencialmente los de la coalición ganadora. Con este desarrollo, se crea una élite nacional consensualmente unificada y rápidamente emerge un régimen democrático estable". ${ }^{7}$

La teoría de élites se encuentra en su etapa de desarrollo. Una de las críticas que ha sufrido (Cammack, 1990), se fundamenta en el reducido espacio otorgado a los sectores populares como agentes de cambio. Los defensores de la teoría de la élite indican que ésta procura enriquecer y no refutar a la teoría de la lucha de clases. $\mathrm{Pa}$ ra Higley, Burton y Field, la explicación de la teoría de la élite en términos de slogan podría ser: "las clases presionan, las élites ejecutan" (classes push, elites efect). ${ }^{8}$ De todos modos, la teoría debe aún ajustar algunas definiciones, especialmente para asumir las pe-

6 Ibídem, pág. 295.

7 Higley and Burton, The Elite variable..., pág. 21.

8 Higley, Burton and Field, In defense of Elite theory..., pág. 424. 
culiaridades de las distintas regiones. Para el caso de Latinoamérica, carece todavía de una satisfactoria incorporación de los movimientos nacionales y populares o fenómenos populistas a la lucha de la élite. Pero justamente por encontrarse en un estadio de crecimiento, resulta aún más atractivo el intento de aplicar estas teorías al estudio de un caso histórico particular.

¿Puede utilizarse la teoría de élites para analizar la evolución política latinoamericana? ¿En qué medida la inestabilidad del régimen de dicha región en el siglo XX puede explicarse a partir del mencionado marco teórico?

Los historiadores concuerdan en considerar el período 18801916 como la "edad de oro" del desarrollo económico argentino. En dicho lapso se produjo la unificación del mercado interno por medio del ferrocarril, la incorporación al mercado mundial y un crecimiento colosal en la producción agropecuaria. Las provincias argentinas que más se beneficiaron con este modelo fueron las del litoral, por las condiciones naturales de la Pampa y la proximidad al puerto. Pero también le cupo un rol destacado en este proceso a provincias del interior como Tucumán y Mendoza. Se incorporaron al modelo mediante una alianza de subordinación, que les reservaba una tarea agroindustrial complementaria con las provincias centrales, lo que les permitiría alcanzar también un espectacular crecimiento.

Antes de 1880, la provincia de Mendoza era un oscuro apéndice de la periferia nacional. Su soporte económico dependía de una producción de subsistencia, combinado con el comercio de ganado con Chile. Su rol en este comercio se limitaba a engordar en sus alfalfares el ganado proveniente de la Pampa Húmeda, para luego conducirlo allende los Andes. A pesar de sus condiciones naturales excepcionales para el cultivo de la vid, la industria vitivinícola en la provincia prácticamente no existía. El número de establecimientos industriales se reducía a un par de decenas, totalmente desprovistos de tecnología moderna.

No obstante, a partir de 1880, la provincia de Mendoza experimentó un crecimiento sin precedentes. La incorporación de capital, tecnología y mano de obra altamente tecnificada de origen 
europeo, transformaron completamente la economía provincial. Se amplió el área cultivada, crecieron las actividades financieras e industriales y en 1908 ya había alrededor de 1.500 bodegas.

El crecimiento económico y el aumento de población, convirtieron a Mendoza no sólo en la cuarta provincia argentina, sino en una entidad con proyección en la política nacional. Los dirigentes mendocinos ganaron un sustancial espacio político en el poder central, y éste ya no pudo ignorar a la provincia andina en la toma de decisiones.

Entre fines del siglo XIX y principios del XX, comenzaron a organizarse en Argentina los primeros partidos políticos. Los tres más importantes fueron el partido conservador, el radical (UCR) y el socialista. ¿Qué desarrollo alcanzó cada uno en la provincia de Mendoza? El partido socialista se organizó muy tardíamente; alrededor de 1915 apenas logró dos cargos para la convención constituyente provincial; un retraso notable, dado que el socialismo de la capital federal ya había obtenido una banca de diputado nacional en 1904. En cambio, los conservadores y los radicales mendocinos lograron organizar partidos vigorosos, que desarrollarían una influencia decisiva en la política nacional de esos años. Los primeros se destacaron en el gabinete nacional, donde les cupo un rol protagonista. Los últimos, en las luchas de la oposición.

Dado que los conservadores controlaban el poder mediante la "máquina electoral" y el fraude, el objetivo principal de la Unión Cívica Radical era la obtención de la libertad electoral. Sus principales líderes, Leandro Alem e Hipólito Yrigoyen, subordinaron su acción política a la obtención del objetivo final. La falta de garantías electorales condujo a la UCR a plantear su lucha fuera del sistema. Combinó la abstención electoral con la revolución armada $(1890,1893$ y 1905) y después de dos décadas de mantener esta estrategia, logró su propósito con la sanción de la llamada Ley Sáenz Peña (1912). A partir de entonces, comenzaría una nueva etapa en la vida política argentina.

¿Qué rol le cupo en la política radical de esos años a la provincia de Mendoza? La respuesta se puede sintetizar en su presencia en las crisis revolucionarias de 1890 y 1905. En la revolución 
de 1890 , no se produjeron hechos de sangre en Mendoza. ¿Implica esto que los futuros radicales no estaban organizados en dicha provincia? Todo lo contrario. Los jefes de la revolución habían dispuesto que sólo se desarrollarían enfrentamientos armados en la capital federal, y que sólo en caso de llegar columnas de cívicos a las ciudades del interior, éstas podrían sumarse al movimiento. Por este motivo, ninguna otra provincia se sublevó, a pesar de existir grupos organizados de cívicos en Córdoba, Santa Fe y Mendoza. ¿Cuál fue entonces el rol de estas provincias? Simplemente, preparar el ambiente político en contra del gobierno y colaborar de alguna manera en los preparativos bélicos de la capital federal.

En términos militares, el radicalismo mendocino marcó su presencia en la conducción de la revolución, dado que la comandancia de artillería le fue confiada a uno de sus líderes, Ricardo Day. Pero el rol más significativo se jugó en Mendoza, especialmente con los actos de oposición al régimen y con la adhesión masiva de dirigentes provinciales a la Unión Cívica, en los meses inmediatamente anteriores a la revolución del Parque.

Pero la relevancia nacional de la UCR mendocina fue aún mayor en 1905. La revolución de ese año se había preparado para estallar en Buenos Aires, Santa Fe, Bahía Blanca, Córdoba y Mendoza. En las tres primeras fracasó rápidamente. En Córdoba alcanzó mayor magnitud, donde incluso se capturó al vicepresidente de la Nación. Pero en Mendoza el triunfo fue completo. El levantamiento se verificó en casi todos los departamentos de la provincia, con la decisiva participación de los civiles. El gobernador debió entregarse, al igual que las unidades de ejército y policía. El líder del movimiento, José Néstor Lencinas, fue nombrado gobernador revolucionario. No obstante, el fracaso del levantamiento en las restantes regiones del país precipitó la represión del intento mendocino por medio del ejército regular, enviado desde Córdoba, San Luis y San Juan.

A pesar de la derrota militar, la revolución radical de 1905 en Mendoza tuve consecuencias decisivas para la evolución política nacional. En 1906, al debatirse la ley de amnistía, los propios conservadores justificaron la actitud de los rebeldes. Con su legitimación, 
el camino quedaba expedito para la reforma electoral. En 1910 asumía la presidencia Sáenz Peña, y dos años después se sancionaba la ley electoral.

La proyección de la acción política mendocina revela la importancia de nuestro objeto de estudio. ¿Qué relación había entre los cívicos de 1890, y los cívicos radicales de 1905? ¿Era el mismo grupo o se trataba de dos facciones diferentes? ¿Qué relación mantenían con los conservadores? ¿En qué medida la unificación o desunificación de las élites radicales y los conservadores afectaron a la inestabilidad del régimen político argentino en el siglo XX?

El eje del trabajo se encuentra en un rastreo de la trayectoria de ambos grupos. La firma del documento de la Unión Cívica en junio de 1890 y la lista policial de presos y exiliados tras la revolución de 1905, suponen la materia prima del estudio. Resta contextualizarla, procesarla y cotejar sus números finales con la teoría de las élites.

\section{Surgimiento de la Unión Cívica en Mendoza: un alud arrollador}

Hacia fines de los 1880, la élite conservadora había ingresado en una espiral excluyente. Una facción procuraba controlar el poder, radiando a los demás sectores de la élite. Las tendencias personalistas que crecían en torno al presidente Juárez Celman, ya habían comenzado a generar amplias críticas. En Buenos Aires, el "banquete de los incondicionales" fue respondido por la oposicion en el "Meeting del Jardín Florida". 9 A partir de entonces las posiciones se radicalizaron. El oficialismo incrementó sus tendencias al favoritismo y sus exigencias de adhesión acrítica para dispensar todo tipo de atenciones, desde préstamos bancarios y nombramientos en la burocracia estatal, hasta lugares en las listas de candidatos. Los opositores se sintieron vigorizados por el éxito del meeting y

9 Lacoste, Pablo: El meeting del Jardín Florida y el origen de los partidos políticos argentinos. "Todo es Historia" (en adelante TEH), XXIII, 267, septiembre de 1989, páginas 6-23. 
el creciente respaldo obtenido en algunos medios de prensa, como "La Nación".

En Mendoza, la oposición se manifestó frontalmente en marzo de 1890. Un grupo de intelectuales, vinculados al Colegio Nacional logró el respaldo de un sector empresarial para fundar "El Debate". Con la dirección responsable de Eduardo Teissaire y Juan de Rosas, el diario se distinguía por las plumas de Agustín Alvarez, Héctor Villars y Julio Leónidas Aguirre, que publicaban notas severamente críticas al gobierno.

En esos días, el oficialismo organizó la visita proselitista a Mendoza de Cárcano, candidato a suceder a Juárez Celman, acompañado por Marcos Juárez, hermano del presidente y gobernador de Córdoba. Las cúpulas conservadoras de Mendoza se aprestaron a brindar una cálida recepción a los visitantes. No obstante, las cosas resultarían muy distintas. En efecto, al llegar a Mendoza, la comitiva oficial fue ampliamente repudiada por grupos de estudiantes del Colegio Nacional. El gobierno de Mendoza intentó controlar la situación, pero sin éxito. A los silbidos siguieron pedradas y la represión policial arrojó un saldo de diez heridos y medio centenar de jóvenes arrestados. ${ }^{10}$

Las autoridades provinciales habían sido humilladas, y procuraron tomar medidas enérgicas para congraciarse con el presidente de la nación. Entre los detenidos estaba Héctor Villars, a quien se acusó de agitar los ánimos de la juventud estudiantil. El gobernador Guiñazú elevó una nota al ejecutivo nacional, solicitando la expulsión de Villars de sus cátedras, ${ }^{11}$ y la medida fue tomada inmediatamente, con la firma del propio Juárez Celman. Con estas medidas, el "Unicato" calculaba intimidar a la oposición. No obstante, el efecto fue justamente el opuesto. Agustín Alvarez publicó en "El De-

10 Diario "El Debate" (provincia de Mendoza), 29 de marzo de 1890, pág. 1.

11 Ibídem, 18 de mayo de 1890, pág. 1. "Buenos Aires, mayo 17 de 1890. Señor Héctor M. Villars: Se le comunica la separación de su puesto de profesor de Latín del Colegio Nacional por Resolución del Ministerio de J. C. e Instrucción Pública. (Firmado: Miguel Juárez Celman, Amancio Alcorta). Y también "Buenos Aires, mayo 17 de 1890. Señor Héctor M. Villars: Se le comunica la separación de su puesto de profesor de francés de la Escuela Normal de Maestros por Resolución del Ministerio de J. C. e Instrucción Pública. Miguel Juárez Celman. Amancio Alcorta." 
bate" una carta abierta a Villars, donde afirmaba "lo felicito y lo envidio". Una pieza extensa, incisiva, audaz; la versión cuyana del "Tu quoque juventud" de Barroetaveña. ${ }^{12}$ El gobernador insistió con su táctica represiva. Solicitó al presidente nuevas medidas de "limpieza" en el Colegio Nacional, ${ }^{13}$ y encarceló a los directores de "El Debate". ${ }^{14}$

12 La nota Tu quoque juventud, publicada en "La Nación" en agosto de 1889, fue un símbolo de la oposición frente a los excesos de verticalismo del gobiemo juarizta y puso en marcha un mecanismo de insospechadas consecuencias. En cierta forma, un rol equivalente le cupo a la carta de Agustín Alvarez ("El Debate", 20 de mayo de 1890, pág. 1), expresada en los siguientes términos: "Mendoza, mayo 18, 1890. Sr. Héctor M. de Villars: Mi estimado amigo: Acabo de ver en "El Debate" de hoy que el Dr. Juárez le ha hecho el insigne honor de destituirlo de las cátedras de Latín y Francés del Colegio Nacional y Escuela Normal. Lo felicito y lo envidio. Me consta perfectamente que era Ud. en el Colegio donde he tenido hasta ayer el honor de ser su colega, el más competente y puntual de los profesores, como me consta también que la participación que tuvo en la silbatina de los estudiantes a Marcos Juárez consistió en defenderlos de los balazos y garrotazos que sobre ellos llovieron y que esto lo hizo en su calidad de ciudadano independiente y en la calle, donde según tengo entendido, no rige el reglamento del Colegio.

Puedo agregar que ha habido profesores que faltaban al $80 \%$ de las clases y que a nadie se le ocurrió "que no reunían las condiciones indispensables para ejercer las funciones de profesor" como dice el decreto de su honorable destitución. Estos antecedentes me habilitan pues para traducir al castellano la mencionada frase y decir, llamando a las cosas por su nombre, que "Ud. no reúne el servilismo indispensable para ejercer las funciones de profesor".

El presidente no ha destituido jamás a ningún partidario incondicional del jefe único del PAN, por más irreversible e indigno que haya podido ser, y en cambio se ha hecho un deber de patriotismo en destituir a todos los empleados que se permitieron el lujo de lo prohibido, es decir, dignidad política. Cuando un jefe único de un partido que ejerce un cargo público, destituye a un empleado honrado porque es independiente de su jefatura política, el decreto respectivo es una patente de independencia.

Como Ud. sabe, ya no soy sargento mayor, empleo que perdí por declinar una excursión a Tierra del Fuego que me proyectó S. E. el Único a pedido de algunos amigos míos, que me atribuían el honrosísimo cargo de ser corresponsal de El Diario de Buenos Aires.

He aplaudido la silbatina estudiantil porque demostró que en Mendoza, los Jóvenes por lo menos son capaces de proceder desinteresadamente y porque quebró el prestigio virgen del caudillo de la taba, representante genuino de la civilización pastora que tan ingratos recuerdos nos ha dejado con Rosas, Facundo y El Chacho y que hoy amenaza hacer retrogradar en 50 años la cultura argentina".

13 Lacoste, Pablo: Mendoza y la Revolución del Parque. "TEH", XXIV, 277, págs. 22-44, julio 1990, pág. 40.

14 "El Debate", 27 de marzo de 1890, pág. 1, denunció que sus directores fueron agredidos y presos por el gobierno. Eduardo Teissaire, uno de los directores, se erigiría años más tarde en el principal operador político de José Néstor Lencinas. Al llegar éste al sillón de San Martín (1918-1920), Teissaire ocuparía el estratégico ministerio de gobierno. Su figura simboliza no sólo la relación entre los sucesos del ' 90 y el radicalismo lencinista de los 1920, sino también entre ambos eventos con el peronismo. Si bien el fenómeno populista de 
Los ataques del gobierno no hacían más que multiplicar el prestigio de los opositores. Poco después (15-6-1890) se firmó el Acta de la Unión Cívica de Mendoza, respaldada por tres centenares de dirigentes. La nueva agrupación incluía intelectuales, miembros de la élite y sectores de la Iglesia - hasta el obispo de Mendoza firmó el Acta. ${ }^{15}$ Después de la revolución de julio, la Unión Cívica multiplicó su espacio político, especialmente con la incorporación del "Club Cívico de los Artesanos".

Este núcleo se había organizado en 1883 para servir como clientela electoral y definir contiendas entre facciones conservadoras. Un caso típico en las luchas de élites, donde una de las facciones en pugna procura el respaldo de las no-élites para vencer a sus adversarios. Pero algunos líderes conservadores reaccionaron con desconfianza. Intuyeron el peligro potencial que conllevaba la existencia de una organización de este tipo, pues en un futuro podía adquirir autonomía y tornarse incontrolable para la élite. Por este motivo procuraron desmantelar el Club de Artesanos, pero sus intentos fracasaron, y en 1890 la organización se incorporó a la Unión Cívica. ${ }^{16}$

mediados del siglo XX ya se desenvolvió en otro ciclo vital, no fue casualidad que Juan Domingo Perón designara a Alberto Teissaire, hijo de Eduardo, para cargos decisivos: presidente del Consejo Superior Justicialista (equivalente al Comité Nacional de la UCR, pero con mucho más poder, dado el carácter vertical del peronismo de aquellos tiempos) y luego vicepresidente de la Nación.

15 Lacoste, Mendoza y la Revolución del Parque, págs. 27, 40-41.

16 Archivo General de la Nación (en adelante AGN), Colección Julio A. Roca (en adelante AR). Emilio Civit a Roca, 16 de febrero de 1883. "El Club de Artesanos es una creación de Serú, los Zapata, Calle y algunos otros, con el objeto de ver modo de contar con esos elementos para lo sucesivo y de trabajar según se asegura públicamente por las candidaturas de Rodolfo Zapata o de Serú para la diputación al Congreso el año venidero. Este Club ha empezado a dar trabajo con el motivo de la elección de dos municipales, pues pretendieron elegir en un principio a Cantos y un La Rosa, antiguos mitristas o tejedoristas, en oposición a Benegas y Sicardi. Ortega ha hablado ya con don José Miguel (Segura, gobernador de Mendoza entre 1881 y 1884) y le ha prometido trabajar porque desistan los artesanos de su propósito y aun ayudarlo a disolver ese Club que además de ser una amenaza para el porvenir, es fomentar y querer crear una entidad independiente y que el día de mañana no podrán dirigir ni los mismos que ahora la manejan.

Ayer fui a ver a José Miguel y de acuerdo con Ortega, le hablé del tal Club y sus propósitos. Aceptaron a Benegas en lugar de La Rosa, pero dejan a Cantos; pero en cuanto a disolver el Club, me ha dado a entender don José Miguel que no lo harán iiporque tiene la seguridad que él lo dirigirá!! y que no hay peligro alguno. No queda pues otro camino a este respecto, que ir poco a poco y con paciencia quitándoles esos elementos hasta obtener su disolución". 
Después de la revolución de 1890 , el oficialismo encontraba cada vez más dificultades para controlar la situación. En un intento desesperado, Guiñazú entregó el ministerio de Gobierno al cívico Julián Barraquero, quien lo asumió con la expresa condición de cumplir el programa de su partido. Sus reformas no fueron aceptadas, y en pocas semanas Barraquero renunció. El gobierno de Guiñazú se desmoronó irremediablemente, y debió presentar su renuncia. La legislatura designó en su reemplazo a Pedro Nolasco Ortiz (octubre de 1891). Poco después, el nuevo gobernador giró hacia el radicalismo. Prácticamente todos los cargos claves fueron controlados entonces por los cívicos radicales. ${ }^{17}$ Incluso en enero de 1892 , el mismo gobernador se adhirió públicamente a la Unión Cívica Radical. ${ }^{18}$

El gobierno impulsó amplias reformas, y los conservadores solicitaron la intervención federal. Alem viajó a Mendoza, y encabezó un plan para armar la provincia con armas chilenas y resistir la intervención por la fuerza. Pero Roca organizó todos los pasos desde el ministerio del Interior, y el interventor Uriburu logró asumir el gobierno de Mendoza sin derramamiento de sangre. ${ }^{19}$

Uriburu analizó cuidadosamente la situación, e informó a Roca de la amplia superioridad política de los cívicos, criterio admitido también por otros líderes conservadores de Mendoza como Civit. ${ }^{20}$ A partir de este diagnóstico, el oficialismo debía negociar con los cívicos radicales desde una posición de inferioridad. Esto se reflejaría en las candidaturas para las elecciones de diputados naciona-

17 Manuel Olascoaga y Ricardo Day fueron designados en los ministerios; José Néstor Lencinas en la Municipalidad; Julián Barraquero y Agustín Alvarez de asesores y el comandante Saturnino Torres al frente de la policía.

18 Olguín, Dardo: José Néstor Lencinas. Mendoza, 1961, págs. 68-69.

19 Lacoste, Pablo: Hegemonía y Poder en el Oeste Argentino, Buenos Aires, 19901991, capítulo VII.

20 AGN, AR, 2. Uriburu a Roca. 9 de febrero de 1892: "La Unión Cívica fue el resultado lógico de esta situación. Era la protesta justa contra tanta inmoralidad. La Unión Cívica representa la inmensa mayoría de la provincia, lo que no sucede en ninguna otra parte". Ibídem. Emilio Civit a Roca. 6 de noviembre de 1890: "la civilización, la riqueza relativa, la nueva vida, ha corrompido a las gentes, las ha enervado, las ha cansado y van al éxito y donde ven el triunfo. $Y$ hoy aquí el éxito es la Unión Cívica y el triunfo no es de Roca". 
les y electores presidenciales de abril de $1892 .{ }^{21}$ Los términos del acuerdo indican la posición de fuerza desde la cual cada sector se sentó a negociar. Los radicales se aseguraban sin lucha el diputado nacional y 5 electores presidenciales; los conservadores apenas pudieron negociar los últimos términos de la lista, justamente aquellos más difíciles de imponer.

En los comicios triunfó la lista mixta de electores presidenciales de la alianza. El radicalismo obtenía cinco votos para Bernardo de Irigoyen, y los conservadores lograban otro tanto en favor de Luis Sáenz Peña. Mendoza había sido el distrito donde la UCR realizó su mejor elección, justamente cuando el candidato conservador obtuvo el $95 \%$ del colegio electoral (el mayor porcentaje de electores de la Historia Argentina, como señala Botana). Además, Agustín Alvarez, el perseguido de la víspera, el presidente de la Unión Cívica, se aseguraba una banca en el Congreso de la Nación. Dado que tanto la conducción de la lista triunfante como las opositoras eran radicales, se calculaba que en breve, el nuevo partido asumiría el control político de la provincia. No obstante, este fenómeno recién se produciría casi tres décadas más tarde.

\section{La división radical}

En 1892 los radicales eran mayoría absoluta en la provincia pero recién llegaron al poder en 1918. Esto se debió fundamentalmente a dos motivos: la división del partido y la habilidad de los conservadores para cooptar al ala radical más próxima a su línea política. ¿A qué se debió la división radical?

El sector liderado por Agustín Alvarez controlaba el aparato del partido. Su criterio político básico consistía en el respeto al sistema vigente ante todo. En el lado opuesto se ubicaba el radi-

21 En las elecciones de abril de 1892 se presentaron dos listas de diez electores, una de radicales lencinistas, y otra de la alianza. En ésta, los cinco primeros términos eran para radicales, y los cinco restantes para los conservadores. Para diputado nacional se presentaron tres listas; los radicales lencinistas llevaban a Pedro N. Ortiz, la alianza apoyaba a Agustín Alvarez, y un tercer grupo tenía como candidato a Ricardo Day. 
calismo "rojo", liderado por Lencinas. Este grupo representaba a otros sectores sociales y mostraba un cierto desdén por el armazón jurídico.

Durante su fugaz gobierno de fines de 1891, el lencinismo ignoró una serie de límites legales, por considerarlos ilegítimos. Por ejemplo, rechazó las atribuciones de la legislatura, alegando su origen fraudulento. Se allanaron domicilios sin orden judicial, para desmontar arsenales privados y dispersar indios cautivos. Se agredía físicamente a los opositores y se ingresaron armas chilenas para intentar resistir la intervención federal. El sector de Lencinas incluía grupos que hasta entonces no habían participado de la vida política. La mayor parte provenían del Club de Artesanos y se jactaban de despreciar las estructuras jurídicas vigentes. En cierta forma, los lencinistas ya se perfilaban como un incipiente movimiento populista.

El ala de Agustín Alvarez, en cambio, admitía la legimitidad del orden vigente, y condenaba los desbordes lencinistas. Estas diferencias se verificaron con nitidez durante el gobierno de Ortiz. Lencinas dirigía "La Reforma", diario que pensaba convertir en una base de acción para impugnar el orden conservador. Solicitó para ello respaldo a los intelectuales del partido, especialmente a Villars, pero éste se negó sistemáticamente a colaborar. ${ }^{22}$ Además, cuando el gobierno de Ortiz apeló a medidas que violaban la constitución, los radicales moderados renunciaron a sus cargos y se sumaron a la oposición. ${ }^{23}$

La expulsión de Lencinas del partido fue un episodio más de este conflicto. El sector de Alvarez controlaba el aparato partidario y entendía que era imposible la comunicación con Lencinas. Por este motivo, el comité provincial tomó la trascendental decisión de expulsar al caudillo del radicalismo. Pero el efecto fue justamente el opuesto. El movimiento popular, incluyendo al Club de Artesa-

22 Diario "Los Andes" (provincia de Mendoza), 17 de enero de 1892, pág. 1.

23 Ibídem, 19 de enero de 1892, pág. 1. "Por estas y otras razones, que han obligado a nuestro representante en el gobierno mayor Ricardo Day a presentar su renuncia, el Comité de la Unión Cívica de Mendoza resuelve declarar que queda el partido completamente desvinculado de la situación oficial de la provincia”. El Comité. 
nos, se fue con Lencinas. ${ }^{24}$ El oficialismo del partido se quedó con la burocracia partidaria, una forma vacía de contenido. Según los analistas conservadores de la época, los dirigentes del comité provincial de la UCR presentaban el cuadro de "el estado mayor de un ejército que ya no existe". ${ }^{25}$

A la ruptura con el movimiento siguió el entendimiento de los radicales azules con los liberales. Los radicales que respondían a Agustín Alvarez se alejaron de Lencinas y fueron a negociar con sus enemigos de la víspera para así vencer a sus correligionarios. Entre febrero y abril de 1892 cristalizaba entonces el "pacto liberal-radical". No habían pasado dos años del frontal enfrentamiento de Agustín Alvarez con los hombres de "el régimen". La prensa ridiculizó este rápido giro, de aquél que había sido el ídolo de la juventud, y ahora negociaba su respaldo a la élite a cambio de una diputación. ${ }^{26}$

Después de la elección citada de 1892, los caminos se abrieron definitivamente para los radicales. El movimiento que respondía a Lencinas pasó a la abstención públicamente a partir de septiembre y reaparecía en la arena política en la revolución de $1905 .{ }^{27}$ Por su parte, el sector de Alvarez inició un largo camino de alianzas con los liberales.

\section{Antecedentes políticos de los cívicos del 90}

Para ponderar la evolución del grupo cívico posterior a 1890 , conviene tener en cuenta la trayectoria anterior de sus miembros. Para ello es preciso dilucidar su participación en eventos políticos representativos a favor $y$ en contra del sistema.

24 Olguín, José Néstor Lencinas, pág. 70.

25 AGN, AR, 62. Uriburu a Roca, 29 de enero de 1892.

26 "Los Andes", 23 de febrero de 1892, pág. 1. "¿Quién lo habrá de creer! El benemérito timbó, el gran patriota del siglo XIX, que primeramente en "La Libertad", luego en "El Debate" y por último desde la tribuna política sobaba la badana que era un primor a los liberales civitistas (...) diciendo de ellos que eran los verdugos de Mendoza, los representantes genuinos del roquismo, los que "nos roban la plata", los parias de la política, etc. ese austero puritano, ídolo en un tiempo de la juventud mendocina, ha renegado de sus principios, de sus convicciones políticas. entregándose en cuerpo y alma al civilismo a cambio de una diputación".

27 Lacoste, Hegemonia y Poder en el Oeste Argentino, capítulo I. 
El hecho político de impugnación del sistema más importante, había sido la revolución de los Colorados de 1866-1867. ${ }^{28}$ ¿QQué rol le cupo en ella a los cívicos? ¿En qué medida los hombres del '90 estaban vinculados con los "colorados"?

Tras realizar el cruce de los revolucionarios de 1866 con los fundadores de la Unión Cívica de 1890, los contactos que aparecen son muy aislados. Apenas cuatro dirigentes tomaron parte en ambos eventos, a los que se les podría agregar dos parejas de padre e hijo, presentes en ambos hechos políticos. ${ }^{29}$ Pero de todos modos, los números no alcanzan para demostrar contacto directo considerable. El análisis de la participación de los cívicos dentro de las estructuras de poder del "régimen", muestra en cambio el fenómeno contrario. Tomando en cuenta el período 1880-1890, los cívicos habían ocupado diversos cargos, incluyendo 29 diputaciones provinciales, una nacional, 6 intendencias, 5 ministerios, tres jefaturas de policía y 8 puestos de elector de gobernador (cuadro I). Los 52 cargos ocupados, reflejan que un cívico de cada 5,5 ya había ocupado un puesto gubernamental en la década anterior.

Por otra parte, dirigentes clave de la Unión Cívica habían militado en la primera línea del "juarizmo". ${ }^{30}$ Además, la vinculación de los cívicos con el "régimen" se descubre también al considerar

28 Masini Calderón, José Luis: Mendoza hace 100 años. Buenos Aires, 1966.

29 Francisco Barraquero y Exequiel Tabanera ocuparon cargos políticos durante el gobierno revolucionario de los colorados (el primero fue intendente y el segundo legislador); sus hijos Julián Barraquero y Exequièl Tabanera (h), respectivamente, firmaron el acta de fundación de la Unión Cívica.

30 Por ejemplo podemos mencionar a Juan Serú, que en 1885 y 1886 había sido vicepresidente del comité pro candidatura Miguel Juárez Celman, y sus dos secretarios, José María Usandivaras y Ezequiel Tabanera (h) también formaron parte en 1890 de la Unión Cívica. El primero de los nombrados, había presidido en 1889 el comité de la juventud juarizta de Mendoza. Entre los que ese año organizaron el comité provincial para consagrar a Juárez Celman como presidente único del PAN, figuraron también líderes que luego dirigirían a la Unión Cívica. Por ejemplo, Daniel Videla Correas fue tesorero del comité juarizta de 1889 y luego vicepresidente de la Unión Cívica. Tres de los cuatro secretarios del mencionado comité del unicato se incorporaron luego a la Unión Cívica: Julio Leónidas Aguirre, Carlos Ponce y Jacinto Alvarez; incluso este último fue presidente de la Unión Cívica. Además, en el gran acto que organizó el comité de 1889 para exaltar a Juárez, uno de los dos oradores fue José A. Salas, que un año más tarde figuraba como vocal ejecutivo de la Unión Cívica. 
los apellidos de los firmantes del acta cívica. En efecto, aparecen reiteradamente los miembros de las familias tradicionales, como Guevara, Godoy, Villanueva, Videla, Lemos, Ortiz, Moyano, Segura, Alvarez, etc. Descendían de los segundones de la nobleza española, que se habían instalado en Mendoza entre los siglos XVI y XVII, y disponían de un amplio poder político y económico. ${ }^{31}$

Por lo tanto no se trataba de la incorporación de un sector nuevo a la vida política. El grupo era más bien una escisión dentro de la propia oligarquía, antes que la irrupción de sectores nuevos en la escena política. Los primeros cívicos no se distinguían del oficialismo en cuanto a extracción social u origen familiar. Pero su discurso cuestionaba algunos aspectos de las prácticas políticas vigentes, y a partir de entonces, se convirtieron en agentes del cambio.

\section{Los cívicos del '90: pautas de cooptación}

Después de 1890, el entendimiento de los "cívicos de la primera hora" con los liberales presentó innumerables alternativas durante cerca de dos décadas. No nos detendremos en las negociaciones particulares, que ya hemos analizado en otra parte. ${ }^{32}$ Nuestro objetivo es analizar cuantitativamente el fenómeno global, es decir, la inserción de los cívicos en el sistema con posterioridad a la organización de su movimiento.

Como en el apartado anterior, se debe considerar la participación de los firmantes del acta del ' 90 tanto a favor como en contra del régimen conservador. Para el primer punto, consideraremos la presencia de los miembros del grupo en la revolución de 1905, mientras que para el segundo, analizaremos los cargos políticos ocupados en las décadas posteriores al '90, especialmente hasta 1905.

$\mathrm{Al}$ igual que lo sucedido en el levantamiento de los Colorados, la participación de los cívicos del '90 en la revolución de 1905 fue

31 Lacoste, Hegemonía y Poder en el Oeste Argentino, capítulo IV; del mismo autor: Los Gansos de Mendoza, Buenos Aires, 1991, capítulo IV.

32 Lacoste, Hegemonía y Poder en el Oeste Argentino, capítulo VII. 
mínima. Apenas seis dirigentes estuvieron en ambos eventos. ${ }^{33}$ Tres de ellos fueron altos dirigentes de la revolución de 1905, pero se trata nuevamente de casos aislados. Análogamente a lo verificado en el caso de los Colorados, no puede hablarse de un vínculo significativo entre el movimiento de 1890 y la revolución de 1905. Inclusive en el episodio de diciembre de 1891, sobre los 50 firmantes de la expulsión de Lencinas de la UCR, 24 habían participado también en la fundación de la Unión Cívica en 1890, especialmente los que entonces habían figurado en la conducción. ${ }^{34}$

Analizando los cargos ocupados por los primeros cívicos después de 1890, aparece nuevamente el fenómeno anterior, pero esta vez mucho más pronunciado. Los firmantes del acta ocuparon entre 1880 y 1905 un número de cargos considerable, entre ellos 43 bancas en la legislatura provincial, 9 en el Congreso, 13 intendencias, 3 gobernaciones, 13 ministerios, 4 jefaturas de policía, 14 cargos de electores para gobernador y 8 presidentes (cuadros II y III). Además, ocuparon 33 bancas en las convenciones constituyentes de $1895,1900,1910$ y 1916 (cuadro III), con lo que totalizaron 140 cargos.

Si en el apartado anterior se puso en claro que los cívicos no eran sectores políticos nuevos, en el presente se demuestra que a partir de 1890 su participación en el régimen no sólo se mantuvo, sino que se incrementó. El cuadro IV compara ambas etapas, y aunque tiene en cuenta las proyecciones relativas para compensar las diferencias cronológicas, demuestra que la presencia de los cívicos en el poder se incrementó a partir de 1890 .

En el período anterior, los cívicos habían ocupado diversos cargos, pero sin alcanzar el primer plano como harían a partir de

33 Florencio Barón, Antenor Pereyra, José Carrión, Pedro Torres, José Palacio y Pastor Echenique.

34 Entre los firmantes del acta de expulsión de Lencinas de 1891, figuraban el presidente $1^{\circ}$ de la Unión Cívica en 1890 (Jacinto Alvarez), los vicepresidentes $1^{\circ}$ y $2^{\circ}$ (Daniel Videla Correas y Emiliano Torres), tres de los cuatro secretarios (Pedro Julián Ortiz, Carlos Lemos y Carlos Ponce), uno de los dos tesoreros (Pompeyo Lemos) y cinco de los quince vocales ejecutivos (Ricardo Palencia, Julio Berutti, Carlos Blanco, Pedro Lobos Amigorena y Antonio Villegas). El listado de las firmantes de la expulsión de Lencinas puede verse en Lacoste, Mendoza y la Revolución del Parque, pág. 43. 
1890. En el decenio anterior, no ubicaron a ningún senador nacional ni alcanzaron nunca la gobernación. No obstante, los tres gobernadores que siguieron a la organización de la Unión Cívica procedieron de su seno: Pedro Anzorena (1892-1895), Francisco Moyano (1895-1898) y Jacinto Alvarez (1898-1901). El último caso resulta especialmente ilustrativo del fenómeno. Jacinto Alvarez fue el primer presidente de la Unión Cívica de Mendoza, y en calidad de tal aparece en la famosa acta de 1890. Hasta entonces no había cumplido una labor relevante en el sistema, pero a partir de ese momento comenzó una espectacular carrera. En 1891 firmó la expulsión de Lencinas de la UCR. En 1892 fue electo ministro provincial, para seguir como diputado entre 1896 y 1897. Renunció a su banca para asumir la vicegobernación, y de ésta pasó al sillón de San Martín por renuncia de Emilio Civit. Y al finalizar su mandato como gobernador, fue consagrado senador nacional por Mendoza (1901-1910).

A partir de los datos analizados, queda de manifiesto que la Unión Cívica no sólo fue una rama desprendida del trono conservador, sino también un excelente canal de ascenso en el poder político. Sumando los 52 cargos ocupados por el grupo entre 1880 y 1890 , a los 141 del período 1880-1905, surge un total de 193 puestos. Dado que los fundadores de la Unión Cívica eran 291, resulta que se distribuyeron más de dos cargos cada tres dirigentes.

\section{Los revolucionarios de 1905}

Tras dejar en claro la proximidad de los conservadores con los cívicos del '90, y la distancia de éstos con los revolucionarios de 1905, resta cerrar el triángulo por la base. Para ello resulta necesario un análisis paralelo, pero sobre los protagonistas de los sucesos de 1905.

¿Cuál era el background político de los revolucionarios de 1905? Entre los cargos ocupados entre 1880 y 1905 en la estructura política del régimen conservador vigente, verificamos cinco intendencias, una diputación provincial y un cargo de elector de 
gobernador. Esto implica menos de un cargo por cada veinte dirigentes de la revolución de 1905. ${ }^{35}$

Los cargos ocupados por el grupo se pueden dividir, según el momento de que se trate, en tres tipos. Entre 1880 y 1890, cuando se iniciaron en la actividad política, y acataban las reglas de juego del régimen ocuparon cuatro cargos. Otro cargo fue desempeñado durante el interregno de 1891 y 1892. A partir del lanzamiento de la abstención de aquel año, sólo desempeñaron dos cargos más.

En líneas generales, la participación de este grupo en la estructura política conservadora fue muy reducida. Al contrario, aparecen reiteradamente en la cárcel por motivos políticos y perseguidos por la justicia, inclusive en pleitos de índole económica. ¿Hubo mayor relación entre este grupo y los revolucionarios de 1866? Ambos eventos tuvieron lugar en ciclos vitales distintos, y por tanto, las posibilidades de participación en ambos por parte de un mismo protagonista, son sumamente reducidas. Sólo se registraron cuatro casos. ${ }^{36}$ Pero hay otros elementos dignos de consideración. Por un lado, la coincidencia entre las críticas conservadoras a ambos levantamientos: "el populacho sublevado" en 1866; "dirección anónima" en 1905. Por otra parte, aparecen algunos dirigentes claves en ambos momentos, como Manuel Olascoaga. Jefe militar de la revolución colorada de 1866, militó en el radicalismo "rojo" entre 1890 y 1892; al ser expulsado Lencinas del radicalismo, Olascoaga siguió su suerte y formó parte de la conducción radical intransigente. Su edad avanzada le obligó a alejarse de la política activa, pero continuó su lucha con la pluma y en 1904, en vísperas de la revolución, publicó El Club de Damas, novela de

35 Los cargos de intendentes fueron desempeñados por José Carrión (1885-1886), Juan Giménez (1889), José Néstor Lencinas (1889-1890 y 1891-1892) y Ramón Videla (1893); Lencinas fue también diputado provincial de 1884 a 1886 y Ramón Videla fue elector de gobernador en 1895 .

36 Tomaron parte de las revoluciones de 1866 y de 1905 Ramón Videla, José Cuitiño, Santos Funes y Ramón Flores. Los tres primeros fueron diputados en la legislatura revolucionaria de 1866. La distancia cronológica permite dos tipos de interpretaciones: o bien estos hombres tenían 20 años en la primera y 70 en la segunda, o bien no se trataría de la misma persona, sino de un hijo, con el mismo nombre u otro homónimo. Con los elementos encontrados, no estamos en condiciones de definir la respuesta. 
ficción que analiza críticamente la situación política de Mendoza y justifica ideológicamente la revolución.

Los dirigentes del ' 90 habían ocupado 193 cargos en el sistema entre 1880 y 1905 , con cuatro lugares en la revolución de los Colorados y seis en la de 1905. Los revolucionarios de $1905 \mathrm{opu}-$ sieron siete cargos oficiales, a cuatro lugares de conducción en los Colorados y seis en el acta de 1890. En el primer grupo, la proporción en favor del sistema es ampliamente superior; por cada actitud en contra, 18 a favor; en cambio, entre los revolucionarios de 1905, las diez posiciones fijadas en contra del sistema superan a las siete de participación en el régimen.

Los apellidos involucrados en la revolución de 1905 también se diferencian de los del ' 90 por no pertenecer a las familias tradicionales. Esta diferencia entre ambos grupos también se ratifica por el análisis de la extracción socioeconómica de los revolucionarios de 1905. En su inmensa mayoría provenían de las clases trabajadoras, y en contados casos se registró algún profesional o propietario relativamente significativo. ${ }^{37}$

Queda entonces suficientemente clara la distinción entre los cívicos de 1890 y los revolucionarios de 1905 . La ruptura de diciembre de 1891, donde la élite radical expulsó al líder carismático del partido, parece haber mantenido su vigencia en el tiempo. El Club de Artesanos y las bases del interior de la provincia que siguieron entonces a Lencinas, reaparecen bajo su conducción en la revolución triunfante de 1905.

\section{Diferencias ideológicas}

En el terreno ideológico también había fisuras entre ambos grupos. Los radicales moderados contaban con más intelectuales, como Barraquero y Alvarez, mientras que las ideas del ala populista seguían la línea más tradicional de Olascoaga y Lencinas.

Agustín Alvarez determinó una línea de ruptura con la figura de los caudillos y la tradición cultural religiosa. Anticlerical de la

37 Lacoste, Hegemonía y Poder en el Oeste Argentino, capítulo IX. 
talla de Voltaire, culminó en lo personal por incorporarse a la masonería en 1905. En materia política, Alvarez creía en la transformación del sistema por evolución; rechazó la abstención revolucionaria de 1892, ocupó una banca de diputado nacional hasta 1896, y luego fue nombrado en distintos cargos. En 1905 estuvo con los leales, y le cupo la responsabilidad de ser juez en el Consejo de Guerra Especial que juzgó a los revolucionarios. En su Historia de Mendoza (1909) mantuvo su condena a la revolución de 1905.

El órgano oficial del radicalismo azul de Mendoza, "El Comercio", mantenía esta misma línea. Medularmente anticlerical, dedicaba una columna diaria especialmente a criticar a curas, prelados, obispos y papas, especialmente de la Edad Media. Admitía la existencia de los fraudes electorales, pero se negaba a la abstención y criticó duramente a la revolución de 1905.

El otro intelectual de los radicales azules era Julián Barraquero. Inicialmente se había enrolado en el krausismo, y conforme a dicha corriente elaboró su tesis doctoral (1879). En dicho trabajo - primera obra escrita importante del krausismo argentino según RoigBarraquero reivindicaba la libertad de sufragio universal, incluyendo a la mujer. Pero con el andar del tiempo, su posición fue girando hacia posiciones más conservadoras, y su proyecto de constitución provincial de 1895, sancionado con el acuerdo de conservadores y radicales azules, imponía el sufragio calificado en la provincia de Mendoza.

En la orilla opuesta, los radicales "rojos" presentaban un programa diferente tanto en materia religiosa y cultural, como política. Convenían en una crítica a la burocracia clerical, pero sin agredir el sentimiento religioso en sí mismo. Olascoaga, en El Club de Damas hace aparecer a un santo sacerdote, que se opone a las connivencias de las cúpulas clericales con los conservadores. Lencinas concluyó el manifiesto revolucionario de 1905 con una reivindicación de la dimensión espiritual (jel radicalismo es Dios, Patria y Libertad!), pero más tarde también respaldó la Reforma de 1918, que pugnaba por liberar a la Universidad de la tutela clerical y reaccionaria. En materia política, tanto Olascoaga como Lencinas descono- 
cían el armazón jurídico conservador. La constitución y la ley habían ignorado a los sectores que ellos representaban, y por lo tanto ellos ignoraban las formas constitucionales. Por este motivo, ningún intelectual de este sector criticaba a los caudillos federales en sus discursos.

\section{Conclusión}

Las luchas de élites cobraron inusitada virulencia en Mendoza entre 1889 y 1892 . Hacia fines de los '80, el grupo hegemónico de la élite no fue capaz de incorporar a las demás facciones al régimen, y surgió una amplia oposición. La Unión Cívica irrumpió en la vida política de Mendoza con la fuerza de un alud arrollador, Presentó una oposición frontal, intransigente y audaz que penetró en distintos ámbitos de la sociedad. Entusiasmó a la juventud estudiantil, consolidó un periódico que desplegaría una amplia influencia, y atrajo al respaldo de los distintos sectores. La acumulación de poder se convirtió en un proceso imparable, y en pocos meses, la situación política de la provincia parecía caer en sus manos como una fruta madura.

Los cívicos de Mendoza eran una facción más de la élite, y su objetivo no era transformar el régimen. Cuando habían acumulado suficiente fuerza, procuraron volver a unirse con las demás facciones, pero con aspiraciones hegemónicas. Comenzó un intento de unificación por "transformación en dos etapas". El acuerdo de un ala de la UCR con las facciones conservadoras, podía echar aparentemente las bases de un régimen estable.

Podían seguir dos caminos alternativos. $\mathrm{O}$ bien, la coalición se consolidaría con el tiempo, y los radicales rebeldes se unirían también, con lo que se lograba el segundo paso de la transformación, o bien éstos persistían en su estrategia anti sistema. Pero la coalición despreció en cierta forma la necesidad de incorporar a los radicales intransigentes. Sus exigencias de libertad electoral no sólo fueron ignoradas, sino que las facciones aisladas sancionaron el voto calificado en la Constitución Provincial de 1895. Los radicales len- 
cinistas no estaban dispuestos a aceptar estas reglas de juego y la revolución de 1905 demostró el fracaso del acuerdo de 1891. ¿Las causas? Probablemente, la resistencia conservadora a abrir nuevos canales de participación.

Como el aprendiz del brujo, los cívicos de la primera hora advirtieron pronto que no podían controlar el movimiento que habían puesto en marcha. Era preciso detenerlo de alguna manera, y en su desesperación, debieron invertir totalmente los roles. Se incorporaron al sistema y lo respaldaron durante dos décadas. A cambio de un número prudencial de cargos, aceptaron la hegemonía conservadora. Si entre 1890 y 1891 habían luchado por la libertad de sufragio, entre 1892 y 1905 obtendrían todo tipo de cargos, junto a los conservadores. En parodias electorales, accederían al poder elegidos por menos del $1 \%$ de la población.

Pero aunque el grupo inicial de cívicos no desarrolló la obra iniciada, ésta no se frustró. Otro sector acudió en su relevo, nutrido de fuerzas sociales distintas: los obreros del Club de Artesanos y los campesinos. El factor integrador de estas nuevas capas sociales para transformarlas en una fuerza política, era la personalidad del líder carismático. Lencinas se había apartado de las estructuras partidarias, y realizaba su trabajo en amplias recorridas por toda la provincia, que lo ponían en contacto directo con las masas. Se conformaba así la base del incipiente movimiento populista que recogería las banderas caídas del '90. Ante la persistencia de los fraudes, el radicalismo lencinista pasó a la abstención revolucionaria en 1892. Los conflictos limítrofes con Chile los obligaron a menguar su actividad política por varios años, pero al superarse el problema, el movimiento se reorganizó. El siguiente acto fue la revolución de 1905, cuyo triunfo, junto al de los radicales cordobeses, abrió el camino para la apertura democrática de 1912.

El radicalismo "rojo" se proclamaba dispuesto a acordar una unidad consensuada con los demás grupos de la élite. Pero exigía sus propias reglas de juego. ¿Aceptarían los conservadores el sufragio universal? A partir de 1912 (6 1916), aparentemente lo hicieron. Pero entonces vendría la contrapartida: ¿Serían capaces los radicales rojos de gobernar respetando los límites constitucionales? 
De estos ítems dependería la nueva unidad de las élites y la estabilidad del régimen político en Argentina. Ni los conservadores estaban plenamente convencidos de reconocer el sufragio universal, ni los radicales intransigentes demostraron capacidad de disciplinar a sus fuerzas para garantizar una administración eficiente.

En el plano específicamente sociológico, surgen también algunas conclusiones de interés. Podemos considerar que la élite de 1890 se dividió en tres sectores: conservadores, radicales moderados o azules y radicales intransigentes o rojos. Los dos primeros acordaron un pacto político, donde reconocían como reglas de juego, el respeto a las formas republicanas, pero sobre la base de la restricción de la participación electoral. Quedó fuera del pacto el radicalismo rojo, que reivindicaba la participación política de las masas, y que no brindaba mayor significado al armazón jurídico. Los radicales intransigentes nunca aceptaron incorporarse a la coalición, pues optaron por no negociar su posición ideológica y por este motivo, no se completó el segundo escalón para alcanzar la "transformación en dos etapas". En su lugar, los intransigentes se mantuvieron en la lucha por el poder fuera del sistema (revolución de 1905).

Con estos elementos, podría ratificarse la validez de la teoría de élites de Higley y Burton para explicar la inestabilidad política en una región de Latinoamérica. Pero se presenta un elemento que no termina de articularse. ¿Es exacto considerar a la rama radical-lencinista como un sector más de la élite? Este grupo incluía solamente a un dirigente encuadrable dentro de dicha categoría. El resto de los protagonistas de las jornadas de diciembre de 1891 y febrero de 1905 , parecen más bien pertenecientes a las no-élites. En 1891, se expulsó a Lencinas por "acudir al comité acompañado por peones y gentes sin arraigo; y al comentar la revolución de 1905, la prensa conservadora de la época comentaba con sorna, la falta de "dirigentes conocidos y respetables" en la conducción del movimiento.

Los hechos parecen reforzar la crítica de Cammack a Higley y Burton: los grandes sucesos políticos no son ejecutados exclusivamente por las élites; cabe a los movimientos de masas un rol preponderante en el devenir histórico, que no puede soslayarse. Los tres autores responden a esta objeción, alegando que las actuacio- 
nes importantes de los movimientos de masas se reducen a casos aislados y esporádicos. Frente a ello, la realidad latinoamericana presenta los movimientos populistas (o nacionales y populares), donde la participación masiva resulta bastante sostenida.

A partir de estos elementos, el trabajo culmina con cuatro propuestas: en primer lugar, se enfatiza en términos generales la importancia de la teoría de las élites, propuesta por Higley, Burton y Field; segundo, sugiere una valoración especial a la definición de élite restringida, propuesta por Lachmann; tercero, llama la atención sobre la importancia de las críticas de Cammack, especialmente en la reivindicación de la importancia del rol de las masas; y cuarto, plantea la necesidad de incorporar el fenómeno de los movimientos populistas para la aplicación de la teoría de las élites en los países latinoamericanos. 


\title{
Cuadros
}

\author{
CUADRO I
}

FUNDADORES UNIÓN CÍVICA DE MENDOZA

CARGOS OCUPADOS ANTES DE 1890

\begin{tabular}{|c|c|c|c|c|c|c|}
\hline Dirigente & $D P$ & $D N$ & $E G$ & $M P$ & $J P$ & INT \\
\hline \multirow[t]{3}{*}{ Alvarez, Agustín } & & & & & $87-89$ & \\
\hline & 81 & & & & & \\
\hline & 88 & & & & & \\
\hline Arroyo, Pedro & $86-88$ & & & & & \\
\hline Astorga, Antonio & 88 & & & & & \\
\hline Barraquero, Julián & & & & $80-81$ & & \\
\hline Berutti, Julio & 84 & & & & & \\
\hline \multirow[t]{2}{*}{ Carrión, José } & & & & & & $85-87$ \\
\hline & & & & & & $87-89$ \\
\hline \multirow[t]{2}{*}{ Civit, Francisco } & $88-89$ & & 81 & & & \\
\hline & & & 87 & & & \\
\hline Guevara, Juan & 86 & & & & & \\
\hline García, Juan & & & & & & 78 \\
\hline Lemos, Pompeyo & $82-84$ & & & & & \\
\hline Lemos, Cruz & & & 87 & & & \\
\hline Latorre, Adolfo & & & & & 87 & \\
\hline Mayorga, Demetrio & & & & & $83-84$ & \\
\hline \multirow[t]{3}{*}{ Molina, Javier } & 80 & & & & & \\
\hline & $82-83$ & & & & & \\
\hline & 85 & & & & & \\
\hline Moyano, Francisco & $89-91$ & & & & & \\
\hline Ortiz, Pedro J. & & & & & & $89-90$ \\
\hline \multirow[t]{3}{*}{ Ponce, José } & 80 & & & & & \\
\hline & $82-84$ & & & & & \\
\hline & $84-86$ & & & & & \\
\hline
\end{tabular}


CUADRO I (continuación)

\begin{tabular}{|c|c|c|c|c|c|}
\hline Dirigente & $D P$ & $D N$ & $E G$ & $M P$ & $J P$ \\
\hline & $86-88$ & & & & \\
\hline \multirow[t]{3}{*}{ Reta, Salvador } & $81-83$ & & & & \\
\hline & $83-85$ & & & & \\
\hline & $85-87$ & & & & \\
\hline \multirow{3}{*}{ Rosas, Pedro } & 81 & & 84 & & \\
\hline & $86-88$ & & & & \\
\hline & $88-90$ & & & & \\
\hline
\end{tabular}

Segura, Federico

$\begin{array}{llll}81-82 & 84-88 & 81 & 87-89\end{array}$

84

Videla, Carlos

84

Videla Correas, D.

$81-84$

84-87

$87-90$

Villanueva, Jorge

87

82

Villanueva, Samuel

80

84

84-86

86-88

88-90

Total

29

01

08

05

03

06

Fuentes: Lista UC: documento de fundación de la Unión Cívica de Mendoza (Archivo Municipal de San Rafael); Cargos: Registro Oficial de la Provincia de Mendoza; Diarios de Sesiones del Poder Legislativo Nacional; listado de convencionales constituyentes de Olascoaga, Laurentino: Instituciones Políticas de Mendoza, La Paz, 1919; listado de legisladores nacionales de la Junta de Estudios Históricos de Mendoza; listado de los jefes de policía preparado por el oficial Gorigoitía (Museo Policial de Mendoza).

Referencias: DP: diputado provincial (el cargo de senador se creó a partir de 1895); DN: diputado nacional (no se registraron senadores nacionales); EG: elector de gobernador; MP: ministro provincial (incluye al director general de escuelas, considerado como ministro de educación); INT: intendente; JP: jefe de Policía. 
CUADRO II

FUNDADORES UNIÓN CÍVICA DE MENDOZA

CARGOS OCUPADOS A PARTIR DE 1890

\begin{tabular}{|c|c|c|c|c|c|c|c|}
\hline Dirigente & $L P$ & $L N$ & $E G$ & $M P$ & $G R$ & INT & $J P$ \\
\hline Aguirre, J. L. & 97 & & & & & & \\
\hline Alvarez, Agustín & 92 & $92-96$ & & & & & \\
\hline Alvarez, Benito & & & 98 & & & & \\
\hline Alvarez, Jacinto & 96-97* & $01-10^{*}$ & & $\begin{array}{l}92 \\
92-93\end{array}$ & $98-01$ & & \\
\hline Anzorena, Pedro & $92-94$ & & & $90-91$ & $92-95$ & & \\
\hline Arroyo, Pedro & $\begin{array}{l}91 \\
94 \\
96 \\
00-02^{*} \\
02-04^{*}\end{array}$ & & & & & & \\
\hline Astorga, Antonio & 91 & & & & & & \\
\hline Barraquero, Julián & $\begin{array}{l}96-97^{*} \\
97\end{array}$ & $\begin{array}{l}98-02 \\
02-06 \\
06-10\end{array}$ & & 90 & & & \\
\hline Cano, Ramón & & & 95 & & & & \\
\hline Cardozo, José M. & & & $\begin{array}{l}95 \\
98\end{array}$ & & & & \\
\hline Ceretti, Manuel & 95 & & 95 & $02-03$ & & $01-06$ & \\
\hline Civit, Francisco & $\begin{array}{l}96-00^{*} \\
04\end{array}$ & & 95 & & & & \\
\hline Day, Arturo & 01 & & & & & 95 & \\
\hline Guevara, Carlos & $\begin{array}{l}99 \\
04\end{array}$ & & & & & & \\
\hline Guevara, Juan & & & 04 & & & 93 & \\
\hline Guevara, Pedro & $\begin{array}{l}92-94 \\
97-01^{*}\end{array}$ & $02-06$ & & & & $95-97$ & $99-00$ \\
\hline Gibbs, Enrique & & & $\begin{array}{l}95 \\
04\end{array}$ & & & & \\
\hline Mayorga, Demetrio & & & & & & & $94-98$ \\
\hline $\begin{array}{l}\text { Moyano, Francisco } \\
\text { Olmedo, Manuel }\end{array}$ & $97-98^{*}$ & & & $98-01$ & $95-98$ & $\begin{array}{l}94-95 \\
00-01\end{array}$ & \\
\hline Ortiz, Pedro J. & : & & & 98 & & $93-95$ & \\
\hline Tomo L, núm. I. 1993 & & & & & & & \\
\hline
\end{tabular}




\section{CUADRO II (continuación)}

\begin{tabular}{|c|c|c|c|c|c|c|c|}
\hline Dirigente & $L P$ & $L N$ & $E G$ & $M P$ & $G R$ & $I N T$ & $J P$ \\
\hline Palencia, Ricardo & $\begin{array}{l}92-94 \\
96-00^{*} \\
02-06^{*} \\
94-96\end{array}$ & & & & & & \\
\hline Ponce, Carlos & $\begin{array}{l}92-94 \\
94-95\end{array}$ & $04-08$ & 95 & 01-04 & & & \\
\hline Ponce, José & 99 & & & & & & \\
\hline Reta, Pastor & & & 95 & & & & \\
\hline Reta, Salvador & & & & & & 91 & \\
\hline Salas, José A. & $04-05 *$ & $00-04$ & & $\begin{array}{l}91 \\
92 \\
97-98 \\
98-00\end{array}$ & & & \\
\hline Serú, Juan & $\begin{array}{l}92-94 \\
94 \\
02 \\
07^{*}\end{array}$ & $98-02$ & & 91 & & & \\
\hline Simonovich, Lucas & & & 95 & & & 94 & \\
\hline Suárez, Enrique & 02 & & & & & & \\
\hline Tabanera, Abelardo & 02 & & & & & & \\
\hline Tabanera E. (h) & $92-94$ & & & & & & \\
\hline Usandivaras, José & & & 98 & & & $\begin{array}{l}91 \\
92\end{array}$ & $\begin{array}{l}93-94 \\
00-01\end{array}$ \\
\hline $\begin{array}{l}\text { Videla Correas, D. } \\
\text { Villanueva, César }\end{array}$ & $\begin{array}{l}95 \\
99 \\
02\end{array}$ & & 95 & & & 92 & \\
\hline Villanueva, Jorge & $\begin{array}{l}95 \\
99\end{array}$ & & & & & & \\
\hline Villanueva, Samuel & $\begin{array}{l}94 \\
96-00^{*}\end{array}$ & & & & & & \\
\hline
\end{tabular}

Fuentes: ídem cuadro $I$.

Referencias: LP: legislador provincial; LN: legislador nacional (ambas columnas incluyen tanto a diputados como a senadores); se diferencia este último con el signo $\left(^{*}\right)$; GR: gobernador; restantes siglas, iguales al cuadro I. 
CUADRO III

FUNDADORES UNIÓN CÍVICA DE MENDOZA

CARGOS OCUPADOS A PARTIR DE 1890

$\begin{array}{ll}\text { Dirigente } & \begin{array}{l}\text { convencional } \\ \text { constituyente }\end{array} \\ \text { presidencial }\end{array}$

$\begin{array}{llllll}1895 & 1900 \quad 1910 \quad 1916 \quad 1892 \quad 1904\end{array}$

Arroyo, Pedro

Astorga, Antonio

Barraquero, Julián

Blanco, Arturo

Calderón, Fernando

Ceretti, Manuel

Civir, Francisco

Day, Arturo

Godoy, Ramón

Guevara, Pedro

Lemos, Manuel

Lobos Amigorena, Pedro

Lucero, Pedro

Mayorga, Demetrio

Moyano, Francisco

Ortiz, Pedro J.

Palacio, Federico

Palencia, Ricardo

Ponce, Carlos

Ponce, José

Salas, José Antonio

Segura, Enrique

Serú, Juan

Tabanera, Exequiel (h)

Vargas, Gregorio

Videla, Juan 


\section{CUADRO III (continuación)}

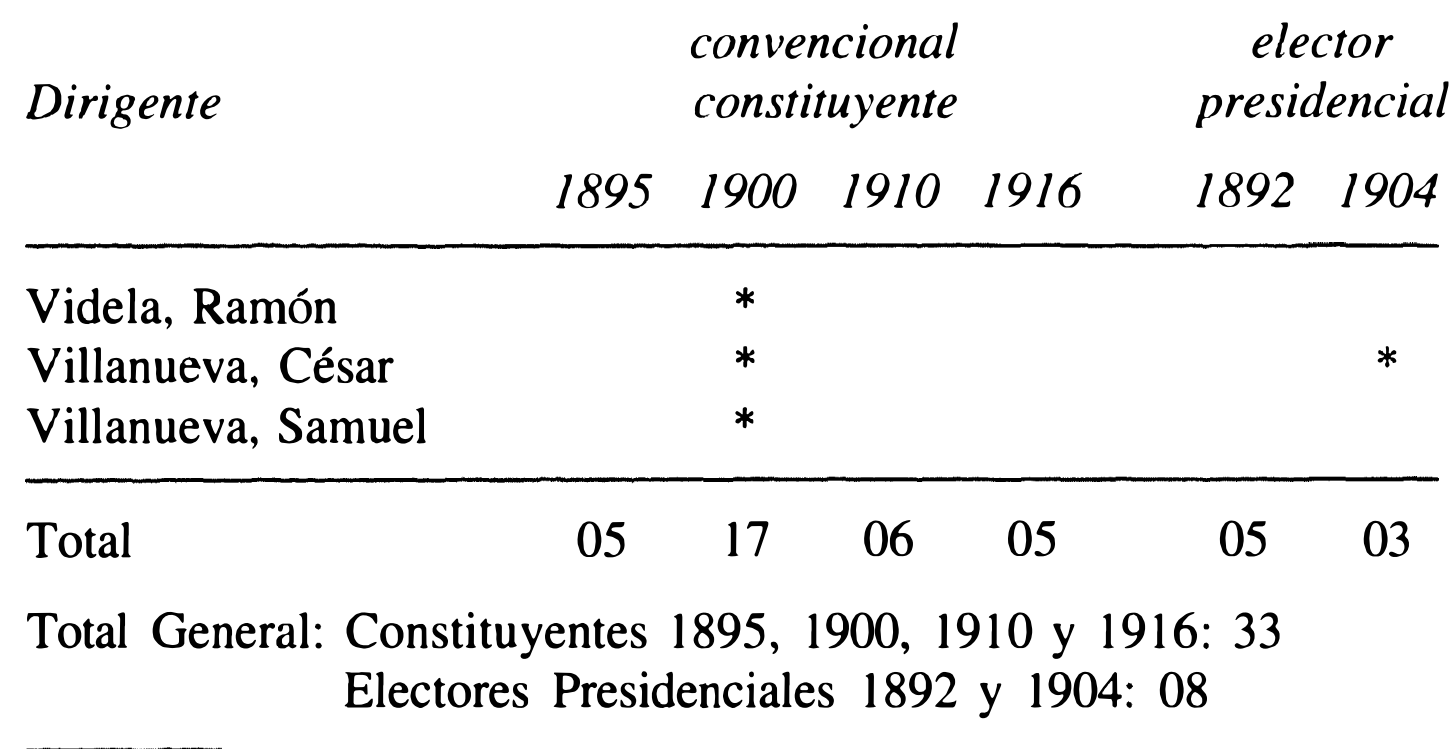

Fuentes: Convencionales: Olascoaga, 1911 y Registro Oficial; Electores: Los Andes y Registro Oficial.

\section{CUADRO IV}

TRAYECTORIA FUNDADORES UC: BALANCE GENERAL (MENDOZA, 1889-1905)

Cargos

1880-1890 1890-1905 Diferencia Total
absol. $x / 10$ absol. $x / 15$ absol. relat. 1880-1905

Fuentes: Idem cuadro I. 